\title{
Impact of pelvic lymph nodes \\ metastasis on recurrence in patients with early cervical cancer
}

R. Montero Macías ${ }^{1,2}$, V. Balaya ${ }^{1,2}$, C. Ngô ${ }^{1,2}$, M. Deloménie ${ }^{1,2}$,

H. Bonsang-Kitzis ${ }^{1,2}$, M. Koual ${ }^{1,2}$, H. Nguyen-Xuan ${ }^{1,2}$, H. Khider ${ }^{1,2}$,

M. Gomes David 1,2, A. Bresset 1,2, J. De Jesus ${ }^{1,2}$, M. Osdoit 1,2, AS. Bats ${ }^{1,2}$, F. Lécuru 1,2.

1. Gynecologic and Breast Oncologic Surgery Department, Georges Pompidou European Hospital, Paris, France 2. Paris University, Faculty of Medicine, Paris, France

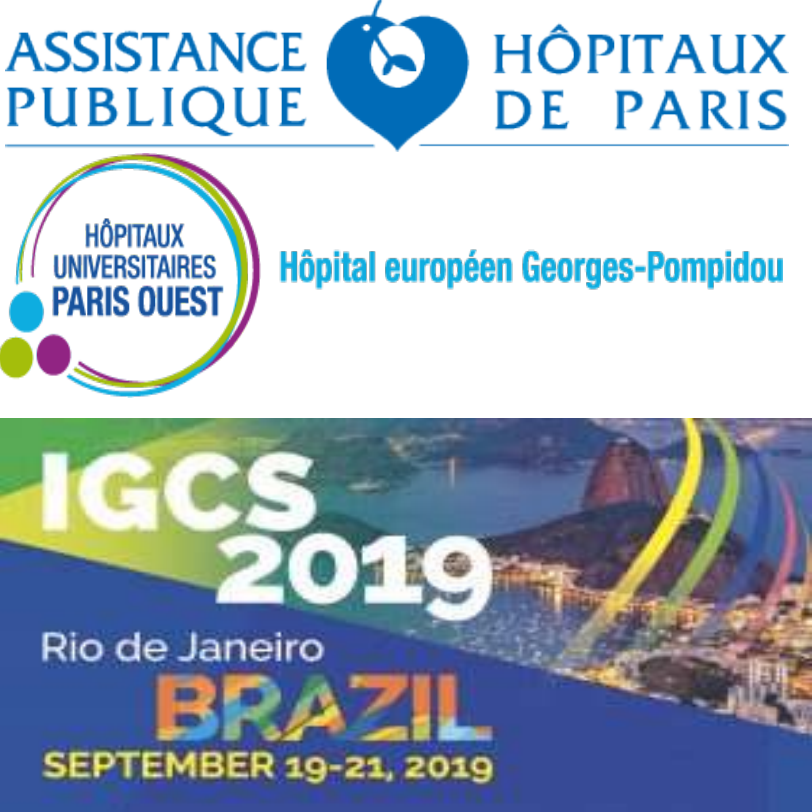

\section{Introduction}

- Lymph node involvement is considered as the main prognostic factor in early-stage cervical cancer.

- Other prognostic factors for recurrence such as tumour size, maximum stromal invasion, and presence or absence of lymphovascular space involvement (LVSI) have also been suggested.

- Depth of invasion parametrial involvement, lymphatic-vascular space invasion, tumor grade and size of primary tumor were shown to be associated with lymph node involvement.

- We aimed to determine the risk factors for lymph node involvement and for recurrence in patients with early-stage cervical cancer.

\section{Material and Methods}

- We retrospectively analysed the data from 85 patients with early cervical cancer treated at the Georges Pompidou's European Hospital in Paris between January 2004 and June 2018.

- Inclusion criteria: patients with cervical cancer stage IA1- IIA.

- Exclusion criteria: missing or insufficient follow-up data (<6 months), no lymph node staging, neoadjuvant chemoradiotherapy.

\section{Results}

Association between patients and tumor characteristics and recurrences.

\begin{tabular}{|c|c|c|c|}
\hline Risk factor & Patients & Recurrences & p \\
\hline $\begin{array}{l}\text { Age } \\
<45 \\
>45\end{array}$ & $\begin{array}{l}35 \\
50\end{array}$ & $\begin{array}{l}6 \\
6\end{array}$ & $0,5(\mathrm{NS})$ \\
\hline $\begin{array}{l}\text { Lymph node } \\
\text { Positive } \\
\text { Negative }\end{array}$ & $\begin{array}{l}14 \\
71\end{array}$ & $\begin{array}{l}3 \\
9\end{array}$ & $0,4(\mathrm{NS})$ \\
\hline $\begin{array}{l}\text { Size of the metastatic deposits within pelvic nodes } \\
\text { micrometastases and ITC } \\
\text { macrometastases }\end{array}$ & $\begin{array}{l}5 \\
9\end{array}$ & $\begin{array}{l}1 \\
2\end{array}$ & 1 (NS) \\
\hline $\begin{array}{l}\text { Tumor size } \\
<20 \mathrm{~mm} \\
220 \mathrm{~mm}\end{array}$ & $\begin{array}{l}57 \\
28\end{array}$ & $\begin{array}{l}3 \\
9 \\
\end{array}$ & 0,02 \\
\hline $\begin{array}{l}\text { FIGO Stage } \\
\text { IAI-2 } \\
\geq \mid \mathrm{B} 1\end{array}$ & $\begin{array}{l}11 \\
74\end{array}$ & $\begin{array}{l}0 \\
12\end{array}$ & $0,3(\mathrm{NS})$ \\
\hline $\begin{array}{l}\text { Lymphovascular space involvement } \\
\text { None } \\
\text { Yes }\end{array}$ & $\begin{array}{l}47 \\
32\end{array}$ & $\begin{array}{l}6 \\
4\end{array}$ & $1(\mathrm{NS})$ \\
\hline $\begin{array}{l}\text { Histology } \\
\text { Squamous cell carcinoma } \\
\text { Adenocarcinoma }\end{array}$ & $\begin{array}{l}61 \\
23\end{array}$ & $\begin{array}{l}7 \\
5\end{array}$ & 0,3 (NS) \\
\hline $\begin{array}{l}\text { Preoperative brachytherapy } \\
\text { No } \\
\text { Yes }\end{array}$ & $\begin{array}{l}75 \\
10\end{array}$ & $\begin{array}{l}10 \\
2\end{array}$ & 0,6 (NS) \\
\hline
\end{tabular}

\section{Conclusion}

- LVSI tended to be associated with positive lymph nodes.
Association between patients and tumor characteristics and pelvic nodes status.

\begin{tabular}{|l|l|l|l|}
\hline Risk factor & Patients & Positive pelvic nodes & p \\
\hline $\begin{array}{l}\text { Age } \\
<45\end{array}$ & 35 & 5 & $0,6(\mathrm{NS})$ \\
$>45$ & 50 & 9 & \\
\hline $\begin{array}{l}\text { B.M.I. } \\
>25 \mathrm{Kg} / \mathrm{m}^{2} \\
<25 \mathrm{Kg} / \mathrm{m}^{2}\end{array}$ & 53 & 8 & $0,6(\mathrm{NS})$ \\
\hline $\begin{array}{l}\text { Tumor size } \\
20 \mathrm{~mm}\end{array}$ & 32 & 6 & \\
\hline $20 \mathrm{~mm}$ & 57 & 9 & 1 (NS) \\
\hline $\begin{array}{l}\text { FIGO Stage } \\
\text { IAl-2 }\end{array}$ & 28 & 5 & $0,2(\mathrm{NS})$ \\
\hline zIB1 & 11 & 0 & \\
\hline Lymphovascular space involvement & 74 & 14 & 0,1 (NS) \\
$\begin{array}{l}\text { None } \\
\text { Yes }\end{array}$ & 47 & 4 & \\
\hline
\end{tabular}

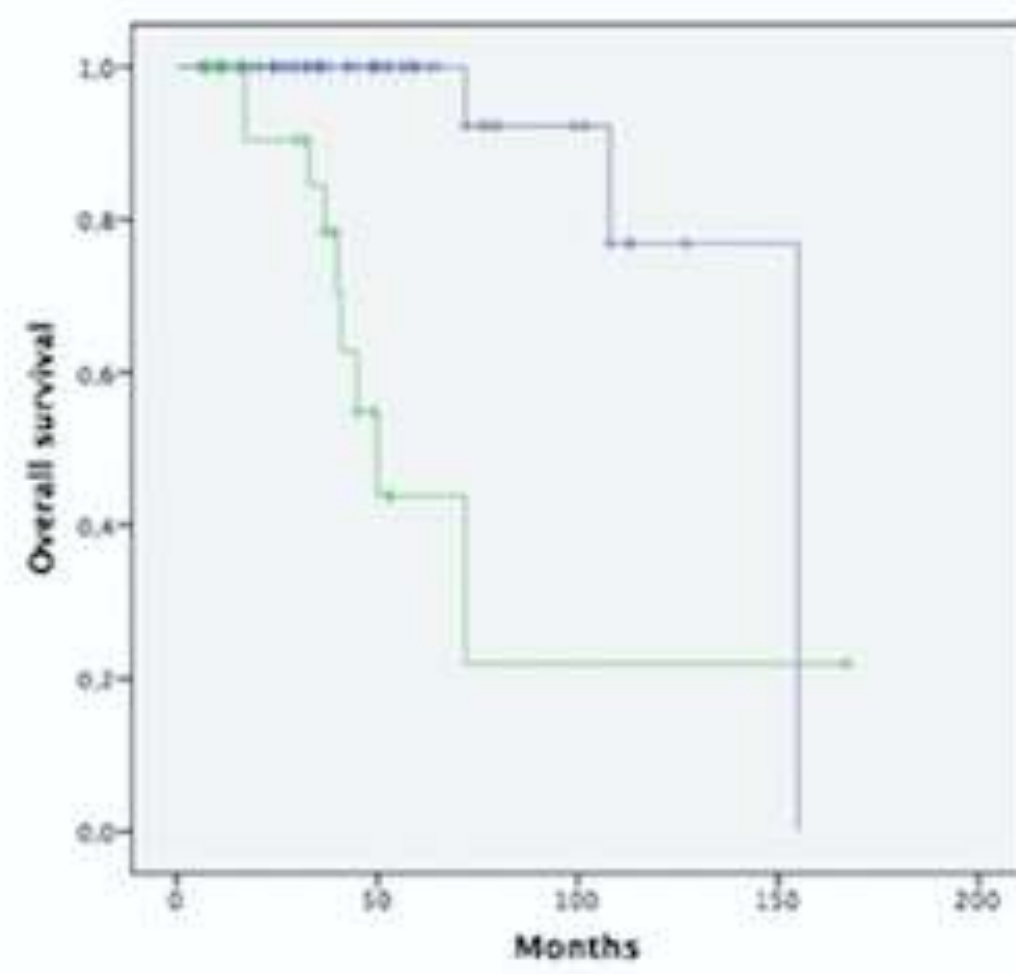

